Ethiopian Journal of Environmental Studies \& Management 8(4): 351 - 363, 2015.

ISSN:1998-0507

doi: http://dx.doi.org/10.4314/ejesm.v8i4.1

Submitted: August 20, 2014

Accepted: April 14, 2015

\title{
MAPPING SUITABLE SITES FOR SETTING UP WIND FARMS: A CASE STUDY OF NYANGA DISTRICT
}

\author{
CHIKOTO, M., ${ }^{1}$ GWENZI, J., ${ }^{2}$ *MARUZIVA, R. ${ }^{1}$ AND BUKA, L.T. ${ }^{1}$ \\ ${ }^{1}$ Department of Geoinformatics and Surveying, University of Zimbabwe \\ ${ }^{2}$ Department of Physics, University of Zimbabwe
}

\begin{abstract}
Due to the negative impacts on the environment of traditional power-generating methods, especially fossil fuels, wind power has increased in popularity. Achieving carbon emissions reduction goals due to the implementation of the Kyoto Protocol require exploitation of renewable energy, Cleaner Development Mechanisms, (CDM). Additionally, the increased difficulty of obtaining oil from foreign sources and continuous power shortages make wind energy a very attractive alternative to keep Zimbabwe powered, clean and green. In order to tap the potential of wind energy sources, there is a need to assess the spatial availability of the resources. Mapping suitable sites for setting up wind farms was the focus of this study. The study employed the Geographical Information Systems (GIS) approach to map the wind energy resources of Nyanga district and carry out a multi-criteria evaluation analysis of their potential by considering other data sets such as land cover, land use and proximity to roads. From the analysis carried out, the mean area size of the most suitable land parcels was $36.810 \mathrm{~km}^{2}$, which is therefore more than enough for a large wind farm given that an area size of $2 \mathrm{~km}^{2}$ is enough to justify the development of a $10 \mathrm{MW}$ wind farm project. Most suitable areas were found where commercial activities are while small patches averaging 5 to $10 \mathrm{~km}^{2}$ in rural areas make the medium suitability areas.
\end{abstract}

Key Words: Mapping, Sites, Wind farm, Energy, Multi-criteria, Evaluation

\section{Introduction}

Climate change is one of the greatest environmental, social and economic threats facing our planet (Hansen et al., 2005). The need to mitigate its effects and the depletion of fossil fuels has led to an increase in the demand for more environmentally friendly renewable energy. These demands have also led to changes in international laws and policies such as the introduction of Cleaner Development Mechanisms (CDMs) due to ratification of the Kyoto Protocol. Under these mechanisms, developed countries can fund renewable energy projects in developing countries in order to reduce greenhouse gas emissions in the world. Wind power is one such form of renewable energy that is expected to encounter a widespread commercial success. Therefore Zimbabwe could benefit through the exploitation of its wind resources.

Over the past two to three years, Zimbabwe has been experiencing electrical power shortages due to the unstable economy and other factors like increased demand for electricity. Energy consumption

*Corresponding Author: Maruziva, R.

Email: maruziva00725@alumni.itc.nl 
has grown at a rate of about $3.5 \%$ in Zimbabwe and agriculture is now consuming $13 \%$ of the available energy (United Nations Environment Program 2012) These recurring electrical power cuts have compelled those people in the business sector mostly farmers to solely rely on the use of fossil fuels (coal and oil) and fuel wood as alternative sources of electrical energy (Scurlock, 2001).

Zimbabwe possesses high altitudinal areas mostly in the Eastern Highlands of the country and high altitudinal areas are characterized with high wind speeds (Wegley, 1980). With the global growth rate of $1.5 \%$ of wind power development per annum Sheppard, (1994) and that wind power is one of the cleanest sources of renewable energy there is need to see the potential of wind energy to produce electricity in Nyanga area. After all, average annual wind speeds of at least 4.0 to $4.5 \mathrm{~m} / \mathrm{s}$ are needed by small wind turbines to produce enough electricity to be cost effective (Elliot D, and Toke D.2000). Past studies done in Zimbabwe for wind power were mainly concerned with technological development of wind turbines rather the wind speed distribution parameters of an area. The wind map which is currently available for Zimbabwe only shows wind speed distribution at a very crude scale. In 1990, a pilot test of a locally manufactured wind turbine (PT 3600) was conducted by a non-governmental organization (NGO) called Regional Environmental Organization (ZERO), (2000). This led to the installation of the turbine in Dumbanwe and Temaruru areas. Currently the turbines are shut down due to many factors including vandalism by the local people; economic hardships leading to lack of spare parts; and lack of sustainability due to ownership issues since there was no sole "owner" responsible for the projects. It is therefore high time
Zimbabwe started capitalizing on the global developments in wind power generation which have led to countries like Denmark having a ninth of its electricity generated by wind turbines (World Wind Energy Association, 2010).

There are basically two types of installation which are wind farms and individual turbines. It has been shown in research that it is necessary to "group wind turbines together so that they are financially and practically viable and to minimize their negative environmental impact." (Brockelhurst, 1999). Therefore the most effective in terms of meeting energy demands is the wind farm approach. However the most explored in Africa is the micro-site turbines. It is therefore necessary to investigate the prospects of wind farms in Africa.

\section{Problem Definition}

Agriculture and Tourism are two of the major contributors to the GDP of Zimbabwe and Nyanga is well renowned in these sectors since it lies in Natural Region 1 characterized by rich soils and a beautiful landscape. In the town of Nyanga is the bustling township of Nyamhuka, around which there is an ever expanding growth of high and medium density housing. On the outskirts are the large scale commercial farms and tourist resorts which are also likely going to expand now that the economy of the country is stabilizing. These changes have led to increased demand for electricity. However, current electrical power shortages in Zimbabwe have been hampering farm and tourism development and have caused indirect environmental degradation in Nyanga. Given that many commercial farms are outside the Zimbabwe Electricity Supply Authority (ZESA) grid, development in their farms is limited because most of their farming appliances require electricity to operate. More so, those that are connected to ZESA 
electricity are facing problems in their operations as there is a widespread electricity shortage in the country.

In an attempt to find alternative sources of energy these farmers and hotel owners are now largely depending on use of generators which use fossil fuels (coal and oil). Other small scale farmers and residents actually cut down trees for fuel wood. The burning of fossil fuels is not environmentally friendly as it pollutes the air by increasing the amount of carbon dioxide concentration in the atmosphere leading to global warming Taylor, (2004). As a counter-measure against increased carbon dioxide emissions, the international community under the Kyoto Protocol introduced measures such as Cleaner Development Mechanisms (CDMs). Wind power is one such alternative of clean and renewable energy and Zimbabwe stands to benefit from exploiting its wind resources.

Considering increased demand for electricity in the country, there is now a need to revamp wind power generation projects. The main focus of this project is to map suitable sites for wind power facilities. In order to make the processes of identifying and locating geographic areas that are suitable, GIS is to be applied for these purposes because it can efficiently collect and view each group of data for consideration. The evaluation of the potential of a region is one of the most important phases in wind farm development and as such the wind maps are fundamental instruments to start any work of planning the installation of a wind farm (ESRI, 2009; Rolf A.de By (ed) 2004).

The objective of the study is to create a map showing suitable sites for setting up wind farms for electricity generation in the Nyanga district. This can be achieved by developing criteria for determining the suitability of a certain area for the placement of wind farms, investigate if there is potential for wind farms or just individual household turbines and create a model for the selection of suitable sites for wind farms.

\section{Research Questions}

1. Is there potential for wind farms or just individual turbines?

2. What are the criteria for the suitability of a given area?

3. Where are the suitable areas?

\section{Study Area}

Nyanga (formerly known as Inyanga) is a district in Manicaland province of Zimbabwe. The town of Nyanga is situated at $18^{\circ} 13^{\prime} 00^{\prime \prime}$ South and $32^{\circ} 45^{\prime \prime} 00^{\prime \prime}$ East in Nyanga district and its average altitude is around $1600 \mathrm{~m}$ above mean sea level; the highest mountain in Zimbabwe (Mt. Inyangani) is found there. Its highest peak is $2600 \mathrm{~m}$. Nyanga district is located adjacent to Nyanga National Park, about $105 \mathrm{~km}$ north of Mutare. The distribution of the air pressure systems in this high latitudinal area governs the high wind flows associated with this area (Wegley, 1980).

Nyanga is found in region I of the agro ecological regions of Zimbabwe which is associated with high rainfall $(1400-1800 \mathrm{~mm}$ per annum) and rich soils. The district is also a popular tourist destination with its trout fishing, golf courses, mountain hikes and holiday resorts. Nyanga also accommodates the highest waterfalls in the country - the Mtarazi Falls are about $760 \mathrm{~m}$ high. The surrounding areas also contain many Stone Age and Iron Age archaeological remains such as pit structures, stone forts, terraces and pathways. 


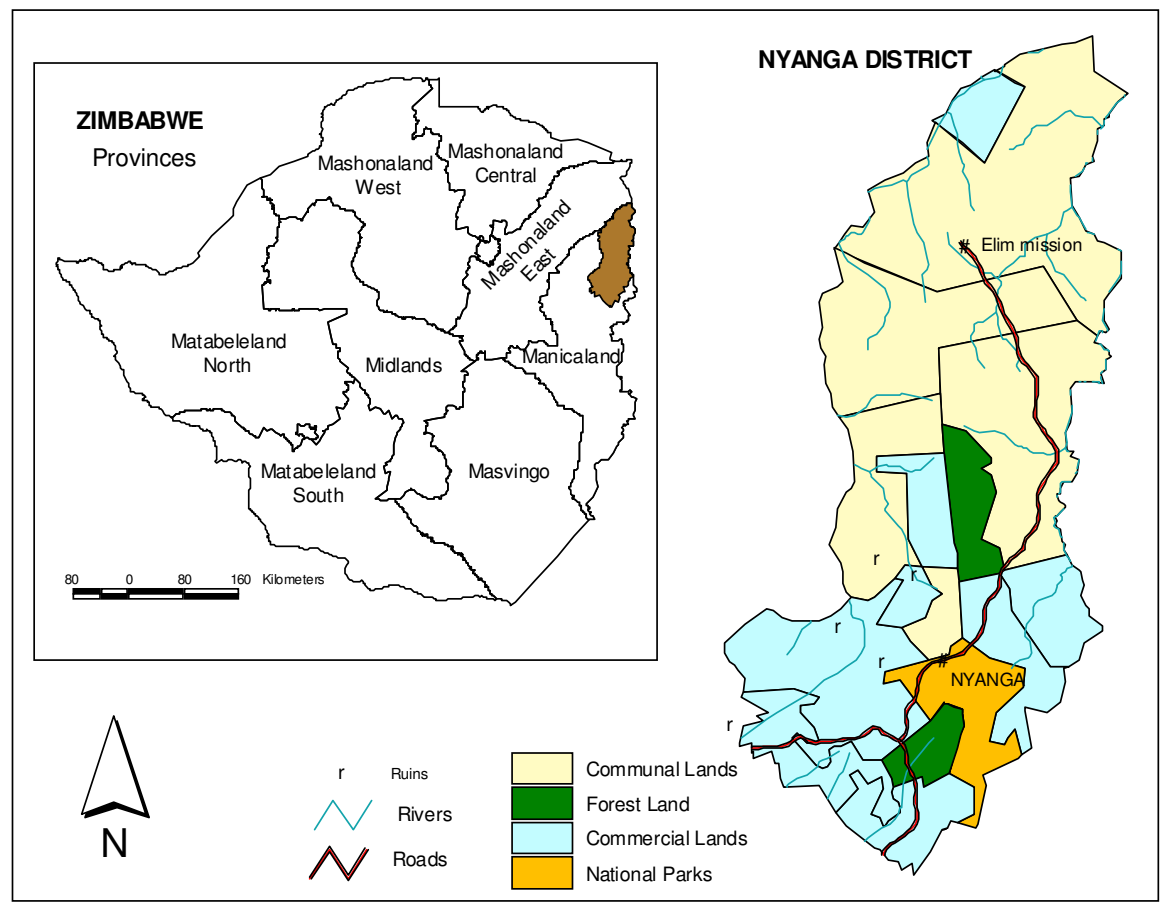

Figure 1: Location of Nyanga District

\section{Methodology}

Site selection for a wind farm is a significant initial step in the process of developing wind energy. This process involves carrying out a multi-criteria evaluation analysis for the purpose of determining most suitable sites for wind power generation. The advantage of wind farm development from a GIS point of view is that it presents a very coherent setting for a decision-making platform which has a fundamentally "geographical" context.

\section{Developing the Criteria}

In Zimbabwe there has not been much focus on wind power generation. As such no by-laws have been included in the Physical Planning Act to govern wind power facility development. However, after some consultation with a well renowned physical planner it was realized that there was need to define criteria for Zimbabwe based on other countries' criteria.

The consultation with the physical planner revealed that criteria developed for the UK, particularly Scotland could be relevant to this project because a lot of its countryside landscape is rugged and mountainous resembling the terrain of Nyanga District. Criteria from the Western Cape Province of South Africa were also used because they include physical features such as urban and industrial; land form and land cover; environmental criteria such as protected areas and topography, and; landscape criteria such as heritage and cultural sites as well as scenic areas. Nevertheless, not all of the criteria were adopted from abroad. The physical planning design manual was very useful as it provided information on the buffer limits for any infrastructural development around power lines, major roads, and residential areas in Zimbabwe.

As a general rule, locating wind farms, in addition to being economically viable, should not have a significant impact on the environment in terms of visual and noise intrusion, electromagnetic interference and possibly wildlife collisions (Kinder et al., 
1996). However, after considering and assessing all the criteria for UK in their "Best Practice Guidelines for Wind Energy Development" and the Western Cape criteria, the following criteria were developed for Nyanga District. The criteria are here listed together with their justification.

\section{Identifying Technical criteria \\ a) Slope}

Generally, high wind speeds occur in more complex terrain and the strongest effect is due to the variation in threshold slope. Therefore the constraint used to define the technical requirement for slope is CRITERIA 1: The slope of the site should be greater than $6 \%$ but less than $13 \%$.

\section{b) Elevation}

As hub heights higher above ground level increase wind power considerably, a complimentary constraint is that the elevation of the site should be higher up the landscape surface. Therefore, the following constraint is considered.

CRITERIA 2: Show all locations whose elevation is at least $50 \mathrm{~m}$.

However, the minimum elevation in Nyanga is $498 \mathrm{~m}$ so in terms of elevation the whole district is suitable. Nonetheless, elevations greater than $50 \%$ would be most suitable.

\section{c) Wind Speed}

A key criterion is the wind speed. Certain minimum average speeds are needed to justify the creation of a wind farm.

CRITERIA 3: Show all locations with an average annual wind speed greater than $5 \mathrm{~m} / \mathrm{s}$.

\section{d) Proximity to Road Network}

For technical and commercial purposes, access to a road network is essential in wind farm modeling. This will generally mean that the site must be within a minimum distance from a national road network to allow for construction vehicles to enter the site and for delivery of materials and general access for supplies and staff.

CRITERIA 4: Identify all sites which are no more than $5000 m$ from all roads.

Also, up to date data of the national power grid is not readily available in digital form at the required scale, a proxy measure was used instead. Using the logic that existing power lines are linked closely with the main road network, we can identify a criteria based around proximity to major roads which effectively models proximity to the national grid. Thus,

CRITERIA 5: Identify sites that are within $5000 m$ of the major road network and by extension existing energy/power networks.

\section{Identifying Environmental Criteria}

\section{a) Planning Restrictions}

The most significant constraints are that limited or no construction should take place within nationally designated nature and science protection areas. Constraints must also be included to protect areas and sites of historic importance. Therefore,

CRITERIA 6: No sites shall be allowed within the boundaries of National Parks, national lands and within 500m of historic sites.

\section{b) Population safety and Impact}

From a planning viewpoint, the social implications brought about by such a project, that is noise pollution safety and aesthetics, dictates that wind farms need to be outside urban/settlement areas. It would also be contrary to health and safety laws. Therefore,

CRITERIA 7: Identify all sites which are more than $500 m$ from built up areas.

\section{c) Water Pollution}

'As a potential variable affecting wind farm location, proximity to water courses is minor criterion. It is, however, important to keep the site away from water in case of flooding and also lessen the minimal contamination of the water course from the 
Mapping Suitable Sites for Setting up Wind Farms................CHIKOTO et al.

wind farm. Thus CRITERIA 8: Identify all sites more than $200 \mathrm{~m}$ from a rivers and dams.

\section{d) Interference}

Vegetation in close proximity could affect wind speed and direction of flow.
Tall trees mainly form the basis of this criterion. Therefore, CRITERIA 9: Identify all sites which are a minimum of $250 \mathrm{~m}$ from existing woodlands.

\section{Defining the Data needed}

The data applied in this site suitability analysis are listed in the table below.

Table 1: Data for the analysis

\begin{tabular}{lll}
\hline Data & Format & Source \\
\hline National roads, rivers, & Shape file & Surveying Dept (UZ) \\
settlements and boundaries & & \\
Wind speed & Excel and JPEG wind roses & Meteorological Office \\
Digital Elevation Model & Raster & Geography Dept (UZ) \\
Land use & Shape file & Geography Dept (UZ) \\
Land cover & Shape file & Forestry Commission \\
\hline
\end{tabular}

\section{Determining the GIS Operations}

Based on the established criteria and data, the next step was to define what operations needed to be performed in order to determine the land suitability. Many layers were converted from vector to raster. Once in raster format, each layer's values needed to be reclassified into a -2 through +2 scoring system. The scoring system was as follows: Least suitability $=-2$; Low suitability $=0$; Medium suitability $=1$ and; High suitability $=+2$. Buffering was done on many layers to determine which values had to be assigned inside/outside the extent of the features and its buffer. For example, rivers were buffered by $250 \mathrm{~m}$. Any areas within that buffer were assigned a value of -2 ; areas outside a value of +2 .

\section{Operations used in this analysis}

Raster to vector conversion

Buffering and Euclidean distances.

Reclassification

Weighted Overlay

Inverse Distance Weighted (IDW) Interpolation

\section{Data Preparation}

After the GIS operations were determined, the data were prepared for the modeling. This included creating new shape files, point maps and surfaces; clipping data to the correct boundaries, and; transforming and georeferencing all the layers into a common coordinate system (WGS UTM Zone 35S) for use in arcGIS9.3.1.

\section{Wind data}

Most of the wind speed data for Manicaland province were acquired from the Met Office in Harare in the form of Excel data and JPEG wind roses. The data were for the period from 1995 to 2005 for 8 met stations including Chisengu, Nyanga Nut orchard, Nyanga Experiment station, Chisumbanje, Mukandi, Buhera, Chipinge, and Rusape. Mean annual wind speeds for the 11 year period were calculated. These data together with the average wind speeds for Chimoio and Tete in Mozambique were used to create a shape file entitled "windspeeds." The Mozambique data were required because there was no weather station further than Chisengu towards the Eastern border of Zimbabwe and Mozambique so the initial interpolation created a wind speed surface which did not cover the whole of Nyanga district. Inverse 
Distance Weighted (IDW) interpolation was done for the whole region to create a "wind speed surface map" and the section for Nyanga district was clipped. The surfaces are illustrated in the figure 2.

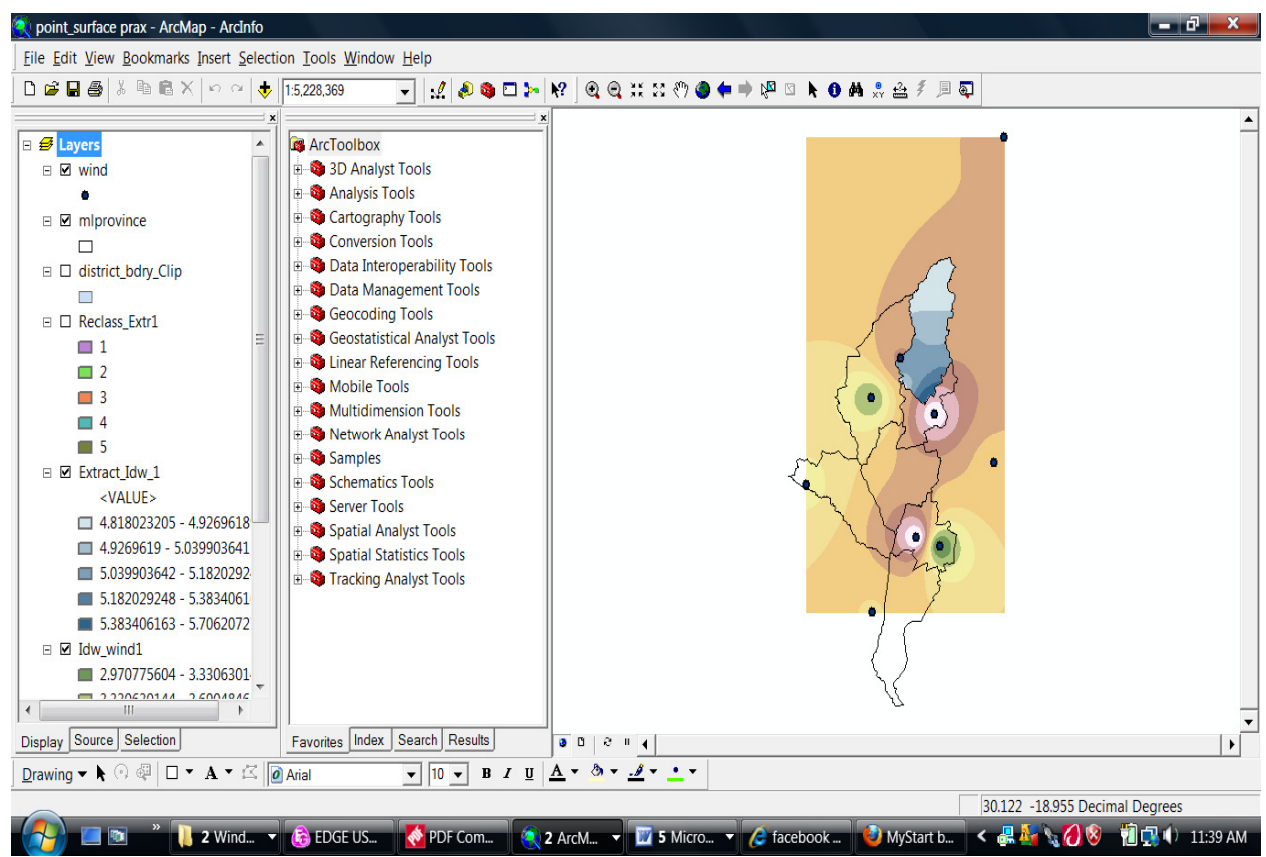

Figure 2: Wind surface maps for Manicaland (brown) and Nyanga (blue).

\section{Other Data}

The land use, land cover, roads, rivers, settlements, places of local importance, boundaries, and historic sites shape files for Nyanga were clipped from the shape files for Zimbabwe. The Digital Elevation Model (DEM) for Nyanga was also clipped from the DEM of Zimbabwe and a Slope surface was created for Nyanga.

\section{Building and Running the Wind farm Site Suitability Model}

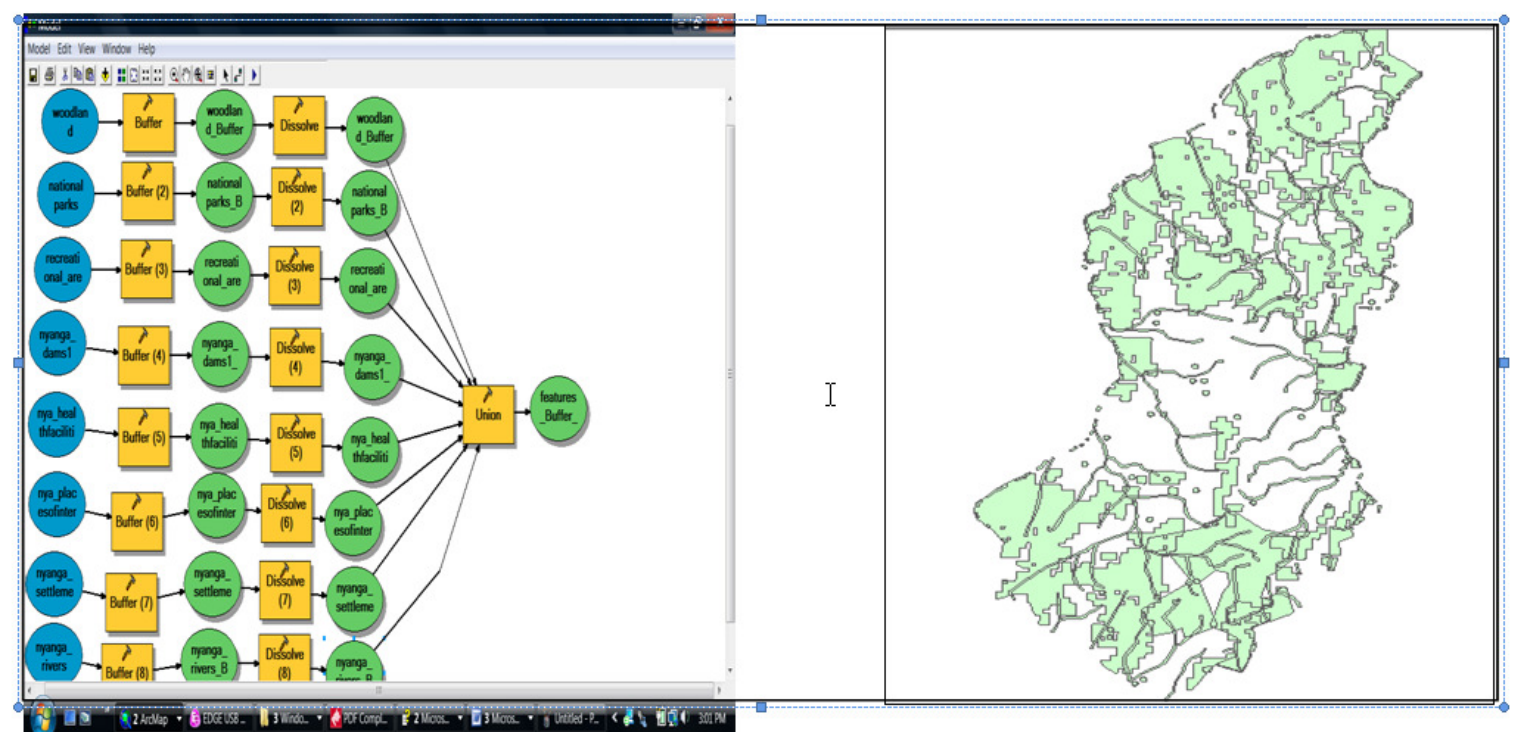

Figure 3: The model including buffer, dissolve, and union tools 


\section{(b) The buffered zones (areas in white were most suitable)}

After preparing all the necessary data layers and adding them to arcGIS, the previously defined criteria were used in the modeling procedure. At this stage it was realized that since many datasets and operations were involved, it was necessary to break down the operations into two models. The first model was used to combine all the layers that had to be buffered using the buffer, dissolve and union tools in Spatial Analyst. The resultant raster was entitled "features." However the "distance from roads" criteria was processed separately because Euclidean distances had to be calculated first and the Nyanga district section was extracted by masking.

The second phase of the modeling involved combining the results of the first model together with the wind speed surface; land cover and land use raster; slope surface; and the roads raster (Euclidean distances). In this model the data layers were reclassified according to the following scale values: Least suitability $=-2$; Low suitability $=0$; Medium suitability $=1$ and; High suitability $=2$.

After reclassification, a weighted overlay operation was carried out on the data in the model according to the following weights.

Table 2: Weights for the weighted overlay

\begin{tabular}{ll}
\hline Data Layer & Weight (\%) \\
\hline Features(buffer distances) & 15 \\
Slope & 10 \\
Wind speed & 40 \\
Land use & 12 \\
Land cover & 8 \\
Euclidean distances (roads) & 15 \\
\hline
\end{tabular}

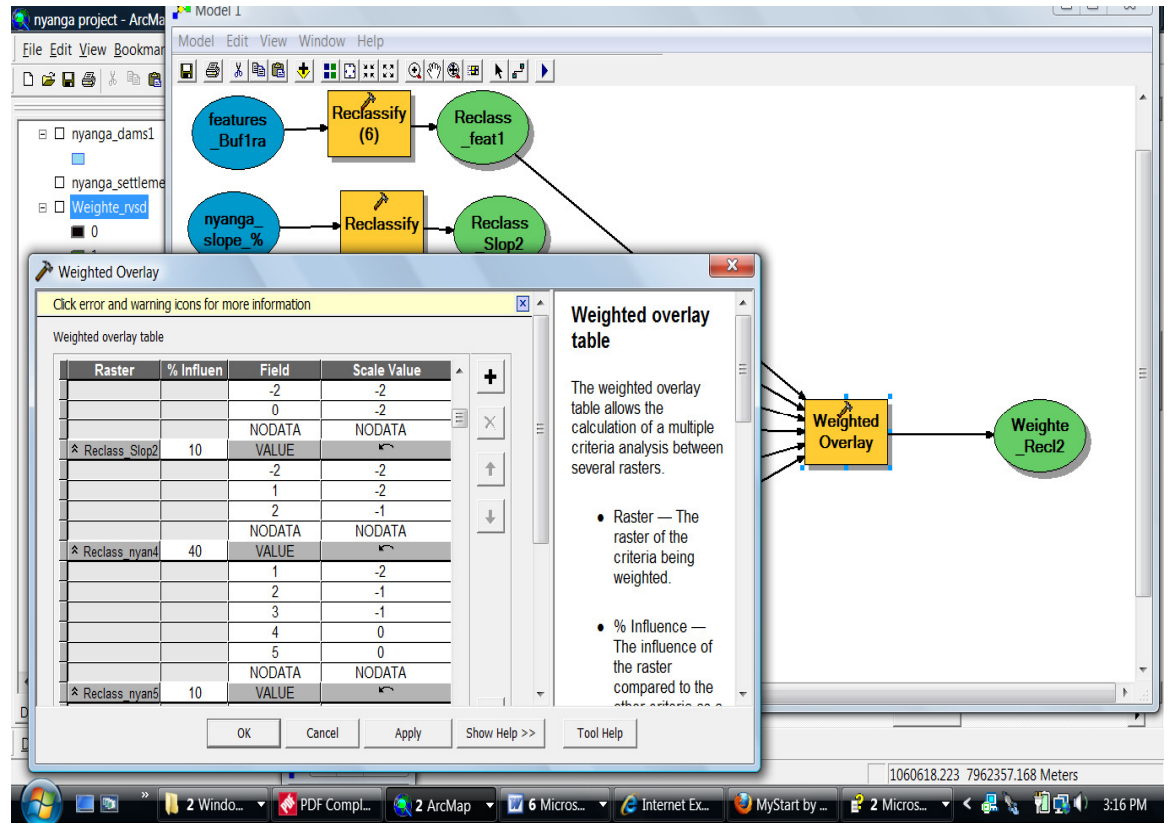

Figure 4: The weighted overlay interface. 


\section{Evaluating the Result}

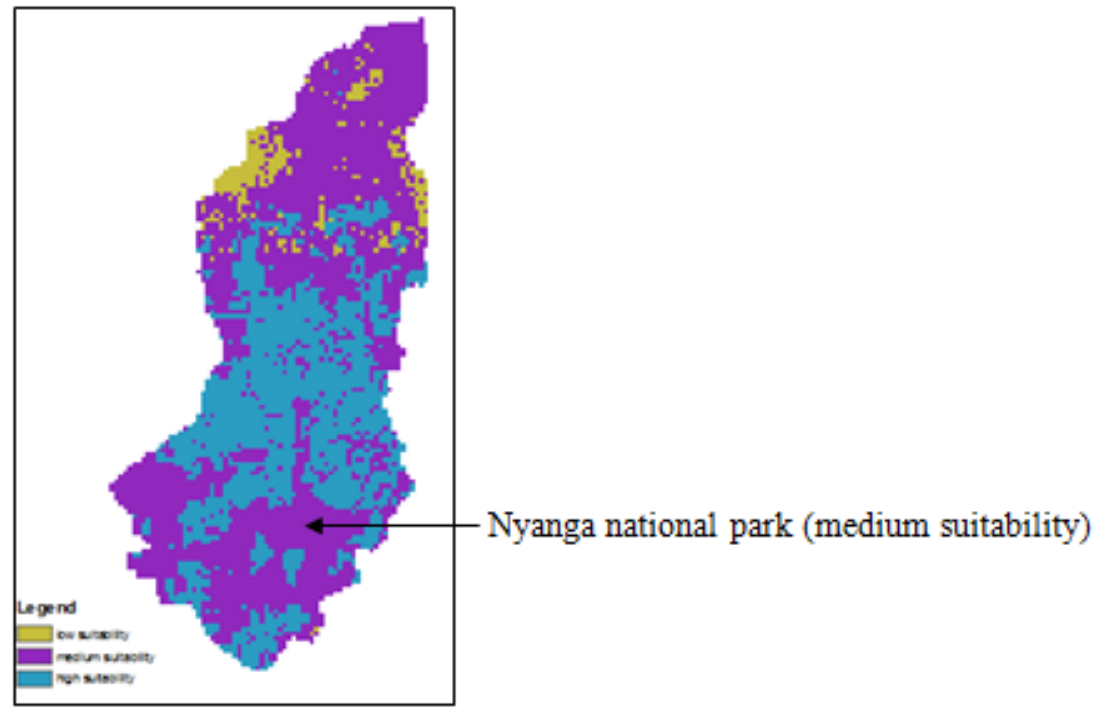

Figure 5: Initial model results

This raster was made into a transparent and overlaid on top of the Nyanga district topographic map in order to evaluate the "suitable sites." The evaluation revealed that some areas in Nyanga national park and Pungwe falls were deemed to be of medium suitability. This was contrary to the scale value of -2 given to such areas. Therefore there was need to modify the criteria of the model.

\section{Modifying the Suitability Model}

The land use layer was reclassified for national parks and woodlands from "least suitable" to "restricted" in the weighted overlay. In addition, the previously discarded criterion of elevation was considered. The DEM was reclassified to give areas at $50 \%$ of the average elevation of Nyanga a scale value of +2 and a weight of $10 \%$ against $90 \%$ for the previous result map. The result of running this revised model is shown in fig 3.5 below

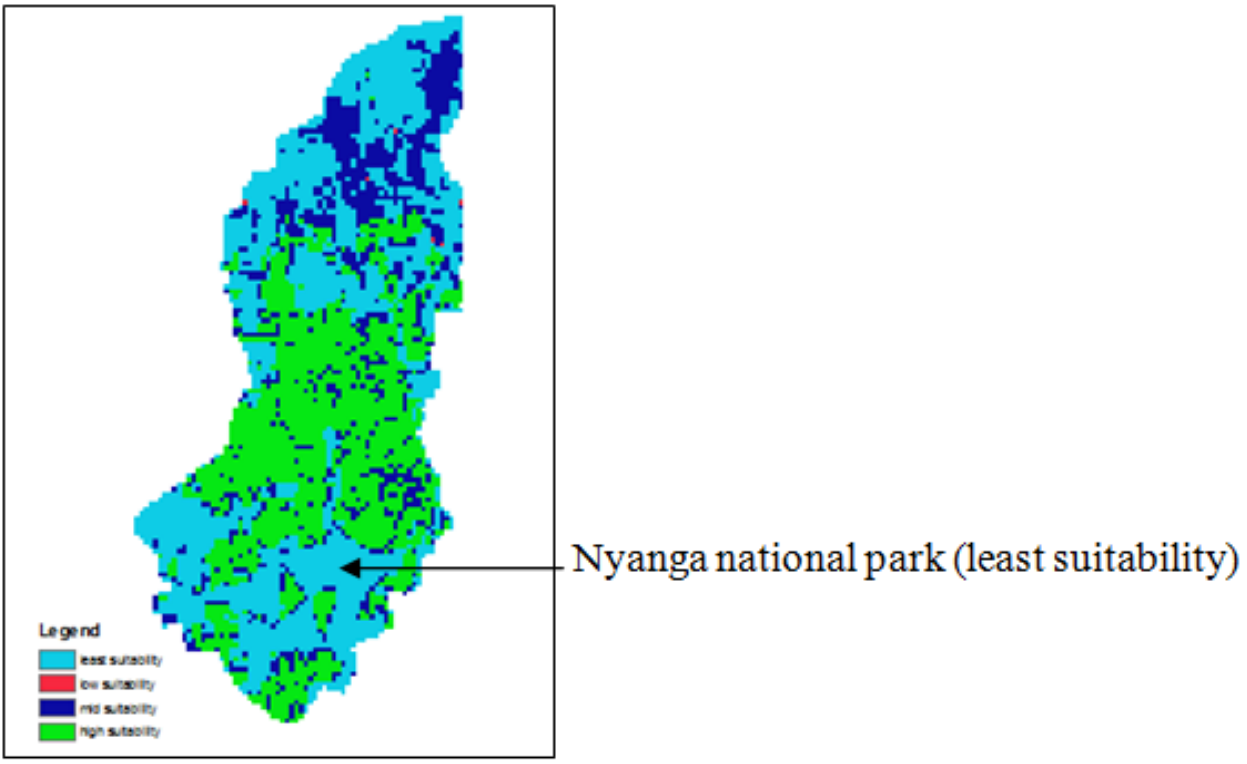

Figure 6: Resultant map for the modified model 
Figure 6 shows the areas which were previously ranked as suitable (now in sky blue) are now least suitable. However, the change from including the height criteria was insignificant in terms of area. The raster was finally converted into a polygon for better representation in the "layout view". The vector map was then edited using the tools available in layout view and the final wind farm site suitability map for Nyanga was created as shown in figure 7.

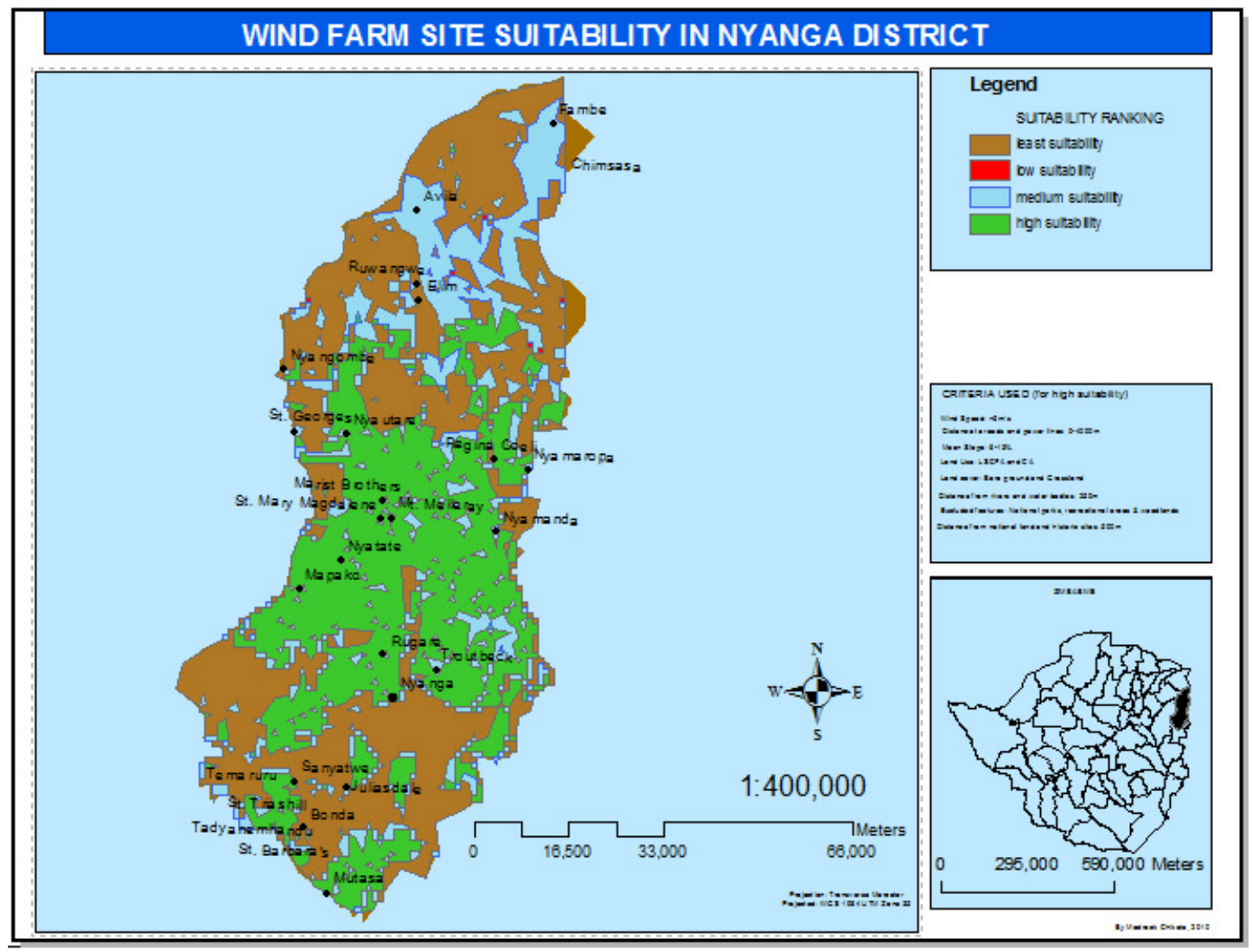

Figure 7: Wind farm site suitability map

\section{Results}

The generated wind farm site suitability map was analyzed in terms of its relevance and potential use.

\section{Minimum Area Size Function}

In order for a possible wind farm site to be deemed economically viable, it should be capable of handling 5 or more $2 \mathrm{MW}$ turbines, or a minimum project size of $10 \mathrm{MW}$, or approximately 2 square kilometers on the ground (Renewable Energy Systems UK, 2009). As such, the goal of this analysis is to identify sites which are approximately 2 square kilometers on the ground. The vector map in Figure 8 below was used to calculate the various areas using the selection and measure tools found in Spatial Statistics. 


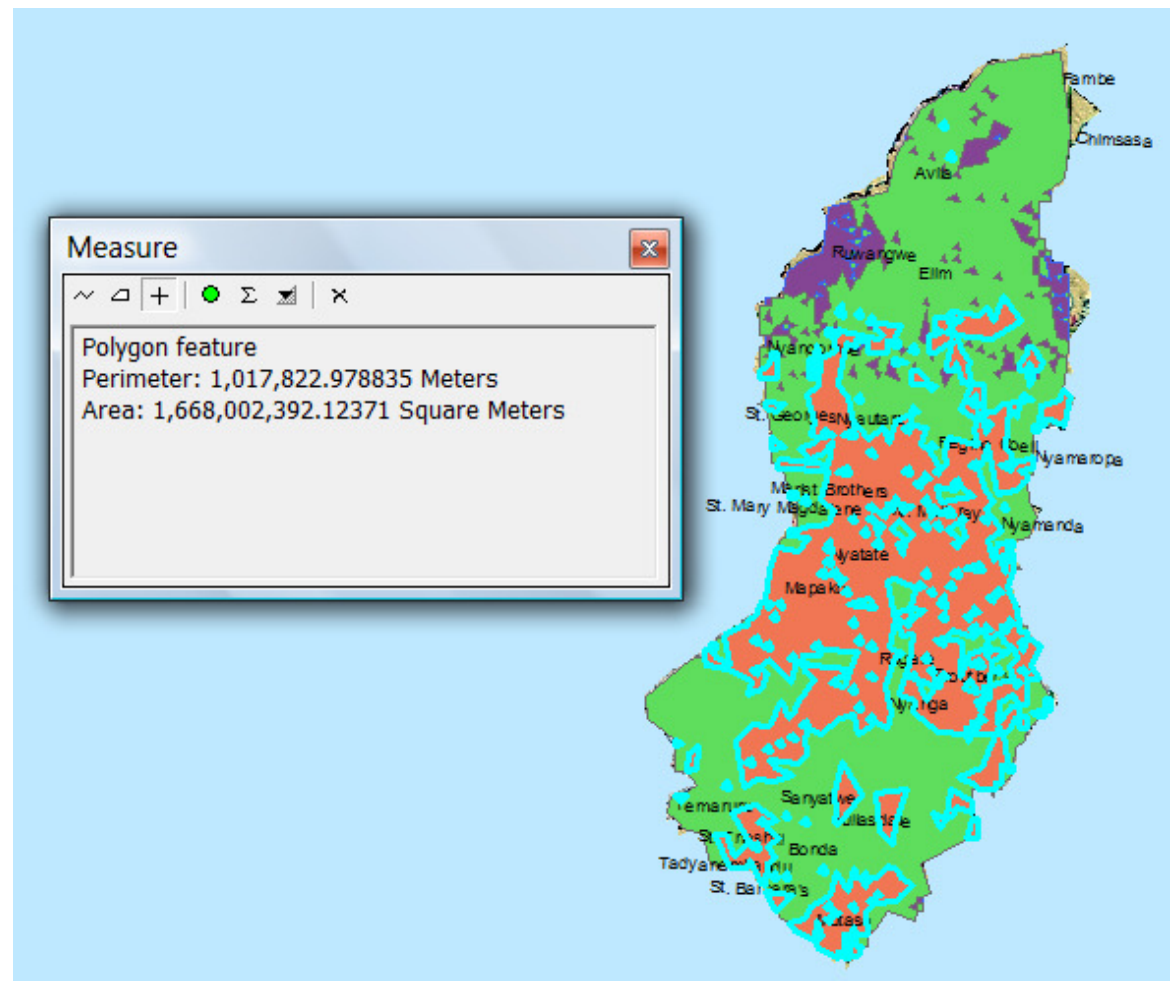

Figure 8: Selected high suitability areas and the measure tool

Table 3: Areas covered by the various suitability rankings

\begin{tabular}{llllll}
\hline Suitability & $\begin{array}{l}\text { Number of } \\
\text { land parcels }\end{array}$ & $\begin{array}{l}\text { Minimum } \\
\text { area(sq.km) }\end{array}$ & $\begin{array}{l}\text { Maximum } \\
\text { area(sq.km) }\end{array}$ & $\begin{array}{l}\text { Mean area } \\
(\text { sq.km })\end{array}$ & $\begin{array}{l}\text { Total area } \\
\text { (sq.km) }\end{array}$ \\
\hline Least & 85 & 0.596 & 988.808 & 29.640 & 2519.418 \\
Low & 6 & 0.903 & 0.903 & 0.903 & 5.586 \\
Medium & 341 & 0.596 & 391.090 & 3.108 & 1059.976 \\
High & 58 & 0.060 & 1676.246 & 36.810 & 2134.995 \\
\hline
\end{tabular}

The above results show that there is very high potential for wind farming in Nyanga district as there are very large swathes of suitable land especially in the most populous areas around the middle lying areas of the district. The land use in these areas is largely commercial activities like large scale commercial farming; business activities (Nyanga town centre), and hotels including Troutbeck. On the other hand, there are also large areas which are least suitable mainly because Nyanga is full of scenic views and beautiful natural landscape like Pungwe falls, Mount Inyangani and Nyanga national park. The areas surrounding these features were "excluded" from the suitability criteria.

Areas of medium suitability are mainly small patches averaging 5 to 10 square $\mathrm{km}$. These areas are mostly concentrated in rural areas because these areas were re-classified as lowly suitable (0) in the weighted overlay analysis. The reason was that demand for electricity in these areas is low compared to commercial areas. However, since the wind speeds in these areas are suitable for wind power generation, most of them were finally deemed to possess medium suitability after running the model. Areas of low suitability only became visible after modifying the suitability model to include elevation. However, as previously noted, their significance is minimum because they are only 6 isolated small patches averaging about 0.9 square kilometers each. 


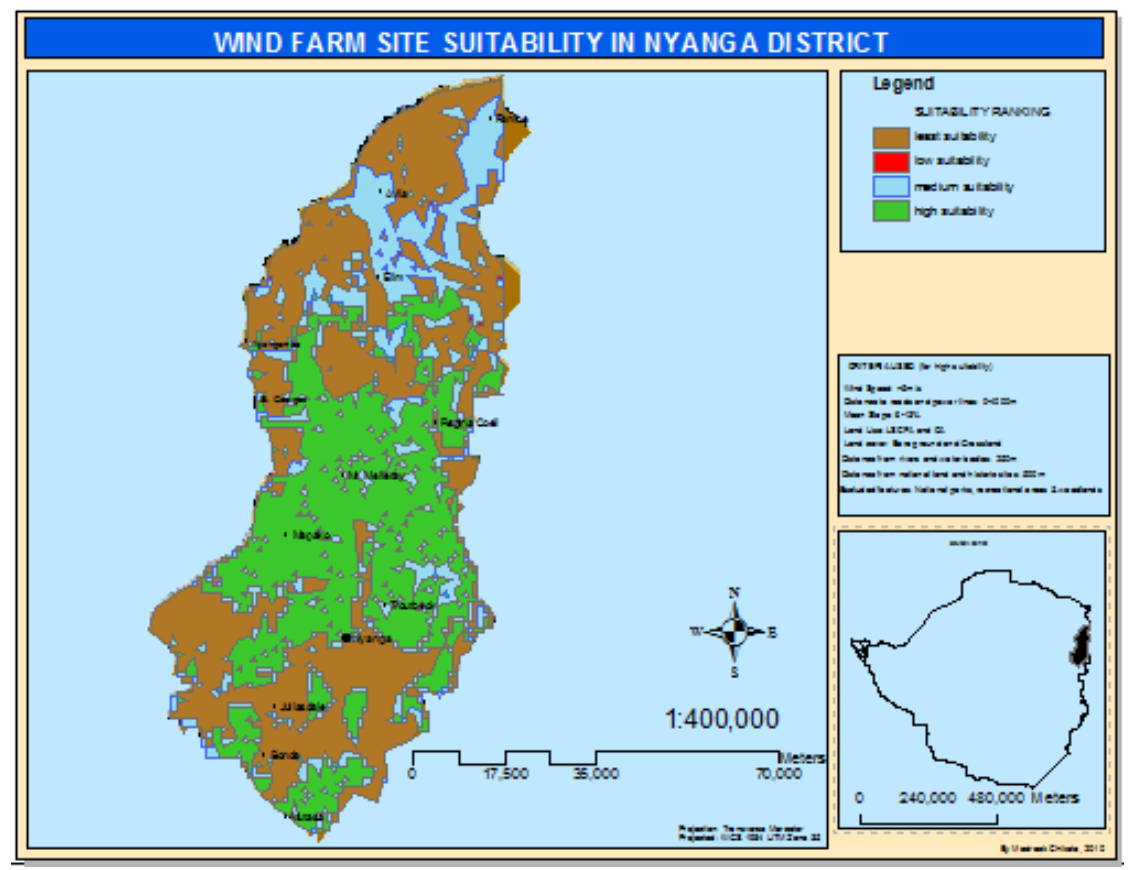

Figure 9: The Wind farm site suitability map for Nyanga District

From the analysis of the results, we were able to identify suitable sites for wind farming in Nyanga district as shown in figure 9. Highly suitable areas were mostly in the mid-lying areas of the district where there is high commercial activity. Most rural areas were found to be of medium suitability while all scenic sites were deemed unsuitable according to the criteria used.

\section{Conclusion}

The goal of this study was to carry out an analysis aimed at mapping suitable sites for setting up wind farms for power generation in Nyanga district.

The most suitable areas, as analyzed, showed that the mean area size of the most suitable land parcels is 36.810 square $\mathrm{km}$. According to Renewable Energy Systems UK (RES, 2009), an area size of 2 square $\mathrm{km}$ is enough to justify the development of a $10 \mathrm{MW}$ wind farm project. Therefore, an average area size of 36.810 square $\mathrm{km}$ is more than enough for a large wind farm.
Highly suitable areas are mostly concentrated in the mid-lying areas of the district where there is high commercial activity. Some of these areas span from Nyanga town through to Troutbeck, Rugare, Mapako, Nyatate, and Mount Melleray and up to Nyautare. Areas of medium suitability are mainly small patches averaging 5 to 10 square $\mathrm{km}$. These areas are mostly concentrated in rural areas, particularly in areas around Elim, Avila and Fambe.

\section{Recommendations}

Future research to improve the accuracy and functionality of the wind farm site suitability map could build on the following recommendations:

- Setting up cup anemometers in various locations of the study area to collect more sufficient and reliable wind speed and direction data in order to refine and obtain most suitable sites.

- Consider using wind modeling software like WAsP instead of IDW interpolation in arcGIS. This will better 
represent the wind speed variations on the wind speed surface map.

- The demographic side of the model could be developed to look at the number of homes served in the vicinity of each site. In this way the practical local benefits of the power supply could be measured.

- A project should be conducted at national level and membership into the World Wind Energy Association is also strongly recommended.

\section{References}

Brockelhurst, M. (1999). The impact of sustainable energy production on land use in Britain, Elsevier, UK.

Chigwada, J.T. (2000). Early lessons for implementation of wind power technology for climate change adaptation, ZERO Regional Environment Organization.

Department of Physical planning (1994). Design Manual, Ministry of Local government, Rural and Urban planning, Government publishers, Zimbabwe.

Elliott, D. and, Toke, D. (2000). A Fresh Start for Wind Power? International Journal of Ambient Energy, Vol. 21.

Hansen, J., Nazarenko, L., Rued, R., Sato M. and Willis, J. (2005). Earth's Energy Imbalance: Confirmation and Implications, American Association for Advancement of Science, 308: 14 -31 .

Kinder D.B. and Dorey M.I. (1996). GIS and visual assessment for landscape planning, University of Kent, UK.
Rolf, A. de By (ed) (2004). Principles of GIS, ITC Educational Textbook Series, International Institute for Aerospace Survey and Earth Sciences (ITC) Enschede,

Scurlock, J. and Ramage, J. (2001). Global renewable energy. In: Kimberly. K .S. (ed.) (2005) Powering our future: An energy source book for sustainable living. Alternative Energy Institute : iUniverse Books p136 - 137

Sheppard, D.G. (1994). Historical development of the windmill. In D.A. Spera, (ed). (1994) Wind turbine technology: Fundamental Concepts of Wind Turbine Engineering, New York: ASME Press.

Taylor, K.E. (2006). 'Climate forcing and climate sensitivities diagnosed from coupled climate model integrations,' Journal of climate, vol. 19, Issue 23.

Renewable Energy Systems (2009). Den Brook wind farm environmental statement.http://www.res.uk.com/den brook/ (accessed 2010).

United Nations Development Programme, http://www.undp.org/un/renewablede velopment/africa/2010report/ (accessed March 2010).

Wegley, H., Orgill, M. and Drake, R. (1980). A Siting Handbook for Small Wind Energy Conversion Systems. Battelle Pacific Northwest National Laboratory, Paperback.

Wind Resource Assessment, http://www.nrel.gov/gis/wind/html (accessed March 2010).

World Wind Energy Association, http:// www.wwindea.org . (accessed March 2010) 